\title{
Analisis Hubungan Kuantitatif Struktur dan Aktivitas untuk Merancang Insektisida Baru Turunan Karbamat Menggunakan Metoda Semiempirik PM3
}

\author{
Agus Dwi Ananto \\ Prodi Farmasi, Universitas Mataram, Nusa Tenggara Barat \\ email:agus_da@unram.ac.id
}

\begin{abstract}
A research has been conducted to investigate the HKSA equation model of a set of carbamic derivative insecticidal compounds based on the hydrofobic, electronic and steric descriptors. The descriptors are calculated by a method of PM3 while the the insecticidal activity are obtained by the experiment. The relationship of the descriptos and the activities are determined by multilinear reggression analysis. The result of the analysis then provide a best equation model that can be used to design new carbamic derivative insecticidal compounds. These design might be recommended to be synthesized in the experimental works.
\end{abstract}

Keywords : carbamic incecticidal, HKSA, hydrofbic descriptor, electronic descriptor, steric descriptor, PM3

\section{PENDAHULUAN}

Penggunaan komputer sebagai peralatan kerja di laboratorium kimia akhir-akhir ini telah dikembangkan menjadi suatu aspek kajian yang disebut dengan Kimia Komputasi. Perkembangan kimia komputasi mengalami fase percepatan pada dekade terakhir ini. Salah satu disiplin ilmu yang sangat terbantu dengan perkembangan tersebut adalah Ilmu Kimia, terutama untuk studi Hubungan Kuantitatif Struktur-Aktivitas (HKSA). Ruang lingkup pembahasan Ilmu Kimia khususnya Kimia Komputasi ini mempunyai sedikit perbedaan dengan kimia teori. Perbedaan tersebut terletak pada penuangan teori-teori kimia ke dalam perangkat lunak komputer dalam bentuk program yang berguna untuk memecahkan masalah-masalah kimia (Istyastono, et.al., 2003).

Keuntungan dari metoda ini adalah dimungkinkannya menghitung sifat molekul yang kompleks dan hasil perhitungannya berkorelasi secara signifikan dengan eksperimen. Hubungan antara struktur-aktivitas biologis dapat dinyatakan secara matematis, hubungan tersebut sering disebut sebagai Hubungan Kuantitatif Struktur Aktivitas (HKSA). Asumsi mendasar dari HKSA adalah bahwa terdapat hubungan kuantitatif antara sifat mikroskopi (struktur molekul) dan sifat makroskopis/empiris (aktivitas biologis) dari suatu molekul. Istilah struktur tidak hanya terbatas pada pengertian pengaturan ruang dan hubungan antar atom dan molekul, tetapi juga sifat fisika dan sifat kimia yang melekat pada susunan tersebut.

Al-Kimia | Volume 5 Nomor 22017 || 100 
Pada eksperimen laboratorium, untuk dapat menemukan suatu senyawa baru yang berkhasiat tinggi diperlukan beberapa langkah eksperimen yang meliputi desain, sintesis, identifikasi, purifikasi dan uji aktivitas. Kelemahan dari strategi eksperimental ini adalah meskipun semua tahapan tersebut telah dikerjakan, namun seringkali produk yang diperoleh ternyata mempunyai aktivitas yang tidak lebih baik dari senyawa-senyawa yang telah ada, sehingga waktu, biaya dan tenaga yang telah dikeluarkan dalam serangkaian kerja laboratorium akan menjadi sia-sia. Sebagai salah satu solusi dari masalah di atas adalah diperkenalkannya pemodelan menggunakan komputer. Dengan pemodelan, sebelum sintesis suatu senyawa dikerjakan terlebih dahulu dapat dicari model hubungan antara struktur, baik elektronik maupun geometri dari satu ataupun sekelompok molekul yang telah dicurigai mempunyai aktivitas tertentu (Mudasir \& Ida, 2003).

Penemuan senyawa baru mencakup banyak bidang sesuai dengan kebutuhan manusia. Pada bidang pertanian, saat ini diperlukan senyawa-senyawa yang dapat berkhasiat sebagai insektisida, fungisida dan herbisida. Salah satu senyawa yang berperan sebagai insektisida adalah karbamat dan turunannya.

Karbamat merupakan insektisida yang berkembang setelah organofosfat. Insektisida ini biasanya mempunyai daya toksisitas yang lebih rendah terhadap mamalia jika dibandingkan dengan organofosfat, tetapi sangat efektif untuk membunuh insekta. Pestisida golongan karbamat ini menyebabkan karbamilasi dari enzim asetil kholinesterase jaringan dan menimbulkan akumulasi asetil kholin pada sambungan kholinergik neuroefektor dan pada sambungan acetal muscle myoneural dan dalam autonomic ganglion, racun atau insektisida jenis ini juga mengganggu system saraf pusat (Teguh, 2009).

\section{METODE PENELITIAN}

Alat

Penelitian ini dikerjakan dengan menggunakan perangkat komputer dengan spesifikasi prosesor Pentium 4 3GHz, RAM 512 MB, Harddisk 60 GB. Perangkat lunak (software) yang digunakan yaitu Hyperchem 7.0 for Windows untuk melakukan pemodelan molekul senyawa, dan perangkat lunak SPSS 13.0 for Windows untuk analisis persamaan HKSA.

\section{Bahan}

Pada penelitian ini data yang digunakan adalah data aktivitas pestisida turunan karbamat beserta data aktivitasnya secara eksperimen yang diperoleh dari literatur (Naik, et al., 2009).

\section{Prosedur Kerja \\ Optimasi Geometri}

Dalam penelitian dengan analisis HKSA metode Hansch, setiap senyawa dibuat model struktur dua dimensinya menggunakan paket program Hyperchem. Model tersebut kemudian dilengkapi dengan atom hidrogen pada setiap atom untuk melengkapi struktur sebenarnya dan dibentuk menjadi struktur tiga dimensi. Proses selanjutnya adalah melakukan optimasi geometri struktur berupa minimasi energi molekul guna memperoleh konformasi struktur yang paling 
stabil. Perhitungan dilakukan dengan metode semiempirik PM3 dengan batas konvergensi 0,001 kkal/Å.mol. Metode optimasi dilakukan berdasarkan algoritma Polak-Ribiero. Setelah diperoleh struktur terstabil, data mulai disimpan dengan melakukan Start log, kemudian dilakukan perhitungan single point, dan dilakukan Stop log untuk mengakhiri proses perekaman hasil perhitungan. Output data selanjutnya dapat dilihat pada file rekaman (file.log). (Tahir, et.al., 2003). Seri senyawa karbamat tersubstitusi yang mempunyai aktivitas sebagai insektisida hasil eksperimen dapat dilihat pada Tabel 1.

Tabel 1. Struktur kimia dan aktivitas senyawa turunan karbamat (Naik et al, 2009)

\begin{tabular}{llllll}
\hline Senyawa & Substituent & Log 1/LD 50 & Senyawa & Substituent & Log 1/LD 50 \\
\hline $\mathbf{1}$ & H & 8.033 & 24 & 3-OMe & 8.12 \\
$\mathbf{2}$ & 2-Et & 8.024 & 25 & 3-OEt & 8.23 \\
$\mathbf{3}$ & 2-i-Pr & 8.45 & 26 & 3-O-i-Pr & 8.033 \\
$\mathbf{4}$ & 2-n-Pr & 8.35 & 27 & 3-O-n-Bu & 7.77 \\
$\mathbf{5}$ & 2-F & 7.97 & 28 & 3-CN & 7.24 \\
$\mathbf{6}$ & 2-Cl & 8.39 & 29 & 3-NO2 & 7.00 \\
$\mathbf{7}$ & 2-Br & 8.43 & 30 & 4-Me & 8.07 \\
$\mathbf{8}$ & 2-I & 8.46 & 31 & 4-Et & 7.95 \\
$\mathbf{9}$ & 2-OMe & 7.86 & 32 & 4-i-Pr & 7.00 \\
$\mathbf{1 0}$ & 2-OEt & 8.4 & 33 & 4-n-Pr & 7.00 \\
$\mathbf{1 1}$ & 2-O-i-Pr & 8.81 & 34 & 4-t-Bu & 7.00 \\
$\mathbf{1 2}$ & 2-O-s-Bu & 7.97 & 35 & 4-F & 8.02 \\
$\mathbf{1 3}$ & 2-O-Allyl & 7.43 & 36 & 4-Cl & 7.00 \\
$\mathbf{1 4}$ & 2-CN & 7.88 & 37 & 4-Br & 7.00 \\
$\mathbf{1 5}$ & 2-NO2 & 7.95 & 38 & 4-I & 7.00 \\
$\mathbf{1 6}$ & 3-Me & 8.31 & 39 & 4-OMe & 7.26 \\
$\mathbf{1 7}$ & 3-Et & 8.17 & 40 & 4-OEt & 7.00 \\
$\mathbf{1 8}$ & 3-n-Pr & 7.06 & 41 & 4-CN & 7.00 \\
$\mathbf{1 9}$ & 3-t-Bu & 7.99 & 42 & 4-NO2 & 7.00 \\
$\mathbf{2 0}$ & 3-F & 8.13 & 43 & 3,4-Me2 & 7.85 \\
$\mathbf{2 1}$ & 3-Cl & 7.86 & 44 & 2-O-i-Pr-5-Me & 8.52 \\
$\mathbf{2 2}$ & 3-Br & 8.31 & 45 & 2-O-i-Bu-3-Me & 8.33 \\
$\mathbf{2 3}$ & 3-I & 8.38 & 46 & 2-O-i-Pr-5-s-Bu & 8.26 \\
\hline
\end{tabular}




\section{HASIL DAN PEMBAHASAN}

\section{Hasil Optimasi Geometri}

Hasil optimasi geometri dari senyawa induk karbamat dapat dilihat pada Gambar 1. Atom C digambarkan dengan bola pejal warna biru muda, atom $\mathrm{O}$ dengan warna merah, atom $\mathrm{N}$ dengan warna biru tua dan atom $\mathrm{H}$ dengan warna putih.

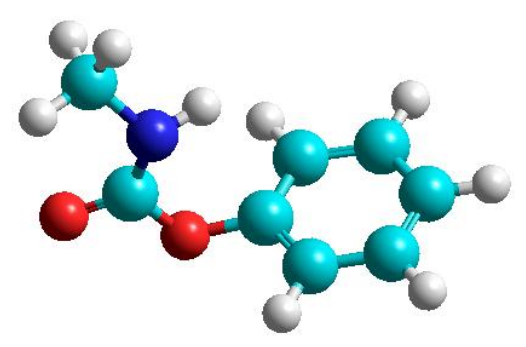

Gambar 1. Hasil optimasi senyawa induk karbamat menggunakan metode PM3 dengan model balls and cylinders

Berdasarkan Gambar 1 dan 2 terlihat bahwa atom O bermuatan negatif. Hal ini disebabkan karena atom $\mathrm{O}$ lebih elektronegatif jika dibandingkan dengan atom-atom lain pada senyawa tersebut, sehingga awan elektron pada atom di dekatnya akan tertarik ke arah atom $\mathrm{O}$ tersebut.

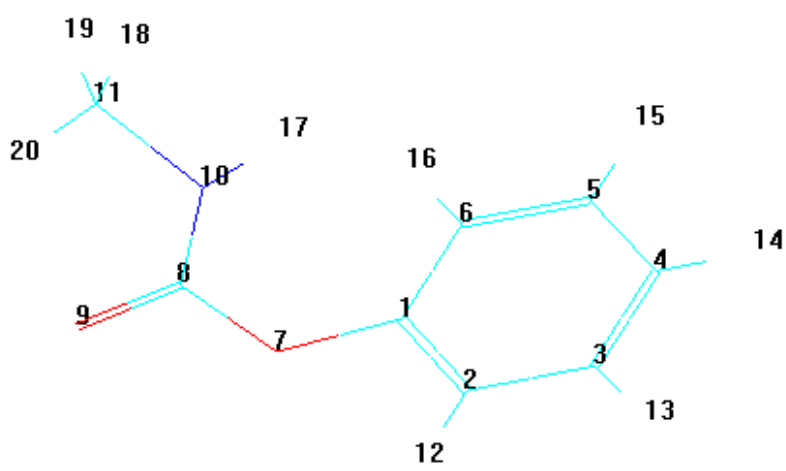

Gambar 2. Hasil optimasi senyawa induk karbamat menggunakan metode PM3 dengan model sticks dan simbol urutan penomoran atom

Pada gugus benzena atom $\mathrm{C} 1, \mathrm{C} 2$ dan $\mathrm{C} 6$ yang terletak dekat dengan atom $\mathrm{O} 7$ mempunyai muatan atom berharga positif karena pengaruh elektronegativitas dari atom $\mathrm{O} 7$, sedangkan atom C3, C4 dan C5 yang letaknya jauh dari atom O7, tidak mendapat pengaruh elektronegativitas dari atom $\mathrm{O}$, sehingga mempunyai harga muatan atom negatif. 


\section{Analisis HKSA untuk Senyawa Turunan Karbamat}

Tahapan yang dilakukan sebelum analisis HKSA yaitu data senyawa turunan karbamat yang telah diketahui aktivitas insektisidanya dibagi menjadi dua, yaitu senyawa fitting dan senyawa uji. Senyawa fitting terdiri dari 39 senyawa untuk membuat model persamaan HKSA. Senyawa uji terdiri dari 7 senyawa untuk menguji validasi model persamaan HKSA yang diperoleh.

Parameter-parameter yang digunakan sebagai variabel bebas dalam analisis HKSA pada penelitian ini adalah parameter elektronik yang terdiri dari muatan bersih atom (q), momen dwi kutub $(\mu)$, energi hidrasi $\left(E_{H}\right)$, polarisabilitas molekular $(\alpha)$, energi total $\left(E_{T}\right)$, energi ikatan $\left(E_{b}\right)$, energi atom terisolasi $\left(E_{\text {at.is }}\right)$, energi elektronik $\left(E_{e}\right)$ dan interaksi inti-inti $\left(E_{\text {int }}\right)$, sedangkan parameter sterik terdiri dari luas permukaan (SA), volume (V), refraktivitas molar (RM), massa molekular (MW) dan panas pembentukan $\left(\Delta \mathrm{H}_{\mathrm{f}}\right)$ adapun parameter hidrofobik terdiri dari $\log \mathrm{P}$. Muatan bersih atom yang digunakan adalah muatan bersih atom dari senyawa induk karbamat, yaitu atom $\mathrm{C} 1, \mathrm{C} 2, \mathrm{C} 3, \mathrm{C} 4, \mathrm{C} 5, \mathrm{C} 6, \mathrm{O} 7, \mathrm{C} 8, \mathrm{O} 9$ dan $\mathrm{N} 10$. Variabel terikat yang digunakan adalah $\log 1 / \mathrm{LD}_{50}$.

\section{Analisis HKSA dengan Metode Analisis Regresi Multilinear}

Pemilihan model persamaan HKSA terbaik tersebut dilakukan dengan memperhitungkan parameter-parameter statistik seperti harga PRESS (Predicted Residual Sum of Square), $\mathrm{r}^{2}$ (koefisien korelasi), adjusted $\mathrm{r}^{2}$, SD (Standar Deviasi), dan $\mathrm{F}_{\text {hit }} / \mathrm{F}_{\text {tab. }}$. Apabila dilihat dari harga $\mathrm{r}$ saja, maka semua model persamaan HKSA mempunyai harga $r$ di atas 0,8 sehingga semua model tersebut memenuhi syarat sebagai model yang baik. Begitu pula untuk parameter $\mathrm{F}_{\text {hit }} / \mathrm{F}_{\text {tab }}$, semua model di atas mempunyai harga $F_{\text {hit }} / F_{\text {tab }}$ lebih dari satu sehingga memenuhi syarat sebagai model yang baik. Jika dilihat dari harga PRESS yang kecil, maka bisa dipilih tiga kandidat model persamaan HKSA yang terbaik yaitu model persamaan no 4, no 10 dan model persamaan no 12. Model persamaan hasil analisis regresi multilinear disajikan pada Tabel 2. 
Tabel 2. Model persamaan HKSA hasil analisis regresi multilinear dengan parameter elektronik, sterik dan hidrofobik

\begin{tabular}{|c|c|c|c|c|c|c|c|c|c|}
\hline Model & Variabel & $\mathbf{r}$ & $\mathbf{r}^{2}$ & $\begin{array}{l}\text { Adjusted } \\
\mathbf{r}^{2}\end{array}$ & SD & $\overline{\mathbf{F}_{\text {hitung }}}$ & $\mathbf{F}_{\text {tabel }}$ & $\mathbf{F}_{\text {hit }} / \mathbf{F}_{\text {tab }}$ & PRESS \\
\hline 1 & $\begin{array}{l}\mathrm{qC} 1, \mathrm{qC} 2, \mathrm{qC} 3, \mathrm{qC} 4, \mathrm{qC} 5, \mathrm{qC} 6, \mathrm{qO} 7, \mathrm{qO} 9, \mathrm{qN} 10, \mu, \\
\mathrm{SA}, \mathrm{V}, \mathrm{E}_{\mathrm{H}}, \log \mathrm{P}, \mathrm{RM}, \alpha, \mathrm{MW}, \mathrm{E}_{\mathrm{b}}, \mathrm{E}_{\mathrm{at} . \mathrm{ss}}, \mathrm{E}_{\mathrm{int}}, \Delta \mathrm{H}_{\mathrm{f}}, \mathrm{Gr}\end{array}$ & 0,944 & 0,891 & 0,723 & 0,230 & 5,317 & 2,297 & 2,315 & 99,758 \\
\hline 2 & $\begin{array}{c}\mathrm{qC} 1, \mathrm{qC} 2, \mathrm{qC} 3, \mathrm{qC} 4, \mathrm{qC} 5, \mathrm{qC} 6, \mathrm{qO} 7, \mathrm{qO} 9, \mathrm{qN} 10, \mu \\
\mathrm{SA}, \mathrm{V}, \mathrm{E}_{\mathrm{H}}, \log \mathrm{P}, \mathrm{RM}, \alpha, \mathrm{MW}, \mathrm{E}_{\mathrm{b}}, \mathrm{E}_{\mathrm{at} . \mathrm{s}}, \mathrm{E}_{\mathrm{int}}, \Delta \mathrm{H}_{\mathrm{f}}\end{array}$ & 0,944 & 0,891 & 0,740 & 0,290 & 5,927 & 2,254 & 2,630 & 33,916 \\
\hline 3 & $\begin{array}{c}\mathrm{qC} 1, \mathrm{qC} 2, \mathrm{qC} 3, \mathrm{qC} 4, \mathrm{qC} 5, \mathrm{qC} 6, \mathrm{qO} 7, \mathrm{qO} 9, \mathrm{qN} 10, \mu \\
\mathrm{SA}, \mathrm{V}, \mathrm{E}_{\mathrm{H}}, \log \mathrm{P}, \mathrm{RM}, \alpha, \mathrm{MW}, \mathrm{E}_{\mathrm{b}}, \mathrm{E}_{\mathrm{int}}, \Delta \mathrm{H}_{\mathrm{f}}\end{array}$ & 0,944 & 0,891 & 0,756 & 0,282 & 6,592 & 2,219 & 2,971 & 84,059 \\
\hline 4 & $\begin{array}{c}\mathrm{qC} 1, \mathrm{qC} 2, \mathrm{qC} 3, \mathrm{qC} 4, \mathrm{qC} 5, \mathrm{qC} 6, \mathrm{qO} 7, \mathrm{qO} 9, \mathrm{qN} 10, \mu \\
\mathrm{SA}, \mathrm{V}, \mathrm{E}_{\mathrm{H}}, \log \mathrm{P}, \mathrm{RM}, \alpha, \mathrm{MW}, \mathrm{E}_{\mathrm{int}}, \Delta \mathrm{H}_{\mathrm{f}}\end{array}$ & 0,942 & 0,888 & 0,764 & 0,277 & 7,142 & 2,191 & 3,260 & 7,108 \\
\hline 5 & $\begin{array}{c}\mathrm{qC} 1, \mathrm{qC} 2, \mathrm{qC} 3, \mathrm{qC} 4, \mathrm{qC} 5, \mathrm{qC} 6, \mathrm{qO} 7, \mathrm{qO} 9, \mathrm{qN} 10, \mu \\
\mathrm{SA}, \mathrm{V}, \mathrm{E}_{\mathrm{H}}, \log \mathrm{P}, \mathrm{RM}, \mathrm{MW}, \mathrm{E}_{\mathrm{int}}, \Delta \mathrm{H}_{\mathrm{f}}\end{array}$ & 0,941 & 0,886 & 0,772 & 0,272 & 7,782 & 2,168 & 3,589 & 219,037 \\
\hline 6 & $\begin{array}{c}\mathrm{qC} 1, \mathrm{qC} 2, \mathrm{qC} 4, \mathrm{qC} 5, \mathrm{qC} 6, \mathrm{qO} 7, \mathrm{qO} 9, \mathrm{qN} 10, \mu, \mathrm{SA} \\
\mathrm{V}, \mathrm{E}_{\mathrm{H}}, \log \mathrm{P}, \mathrm{RM}, \mathrm{MW}, \mathrm{E}_{\mathrm{int}}, \Delta \mathrm{H}_{\mathrm{f}}\end{array}$ & 0,940 & 0,883 & 0,778 & 0,268 & 8,416 & 2,151 & 3,912 & 60,165 \\
\hline 7 & $\begin{array}{c}\mathrm{qC} 1, \mathrm{qC} 2, \mathrm{qC} 4, \mathrm{qC} 5, \mathrm{qC} 6, \mathrm{qO} 7, \mathrm{qN} 10, \mu, \mathrm{SA}, \mathrm{V}, \mathrm{E}_{\mathrm{H}}, \\
\log \mathrm{P}, \mathrm{RM}, \mathrm{MW}, \mathrm{E}_{\mathrm{int}}, \Delta \mathrm{H}_{\mathrm{f}}\end{array}$ & 0,937 & 0,877 & 0,778 & 0,268 & 8,820 & 2,139 & 4,124 & 124,582 \\
\hline 8 & $\begin{array}{c}\mathrm{qC} 1, \mathrm{qC} 2, \mathrm{qC} 4, \mathrm{qC} 5, \mathrm{qC} 6, \mathrm{qO} 7, \mathrm{qN} 10, \mu, \mathrm{SA}, \mathrm{V}, \mathrm{E}_{\mathrm{H}}, \\
\log \mathrm{P}, \mathrm{RM}, \mathrm{MW}, \mathrm{E}_{\mathrm{int}}, \Delta \mathrm{H}_{\mathrm{f}}\end{array}$ & 0,936 & 0,875 & 0,785 & 0,264 & 9,651 & 2,131 & 4,528 & 25,010 \\
\hline 9 & $\begin{array}{c}\mathrm{qC} 1, \mathrm{qC} 2, \mathrm{qC} 4, \mathrm{qC} 6, \mathrm{qO} 7, \mathrm{qN} 10, \mu, \mathrm{SA}, \mathrm{V}, \mathrm{E}_{\mathrm{H}}, \mathrm{Log} \\
\mathrm{P}, \mathrm{RM}, \mathrm{MW}, \mathrm{E}_{\mathrm{int}}, \Delta \mathrm{H}_{\mathrm{f}}\end{array}$ & 0,932 & 0,868 & 0,782 & 0,266 & $\begin{array}{c}10,09 \\
4\end{array}$ & 2,128 & 4,743 & 21,404 \\
\hline 10 & $\begin{array}{c}\mathrm{qC} 2, \mathrm{qC} 4, \mathrm{qC} 6, \mathrm{qO} 7, \mathrm{qN} 10, \mu, \mathrm{SA}, \mathrm{V}, \mathrm{E}_{\mathrm{H}}, \log \mathrm{P}, \\
\mathrm{RM}, \mathrm{MW}, \mathrm{E}_{\mathrm{int}}, \Delta \mathrm{H}_{\mathrm{f}}\end{array}$ & 0,923 & 0,852 & 0,766 & 0,275 & 9,892 & 2,130 & 4,645 & 13,078 \\
\hline 11 & $\begin{array}{c}\mathrm{qC} 2, \mathrm{qC} 4, \mathrm{qC} 6, \mathrm{qO} 7, \mu, \mathrm{SA}, \mathrm{V}, \mathrm{E}_{\mathrm{H}}, \log \mathrm{P}, \mathrm{RM}, \mathrm{MW}, \\
\mathrm{E}_{\mathrm{int}}, \Delta \mathrm{H}_{\mathrm{f}}\end{array}$ & 0,916 & 0,840 & 0,757 & 0,281 & $\begin{array}{c}10,09 \\
3\end{array}$ & 2,136 & 4,724 & 32,271 \\
\hline
\end{tabular}


Dari model-model persamaan HKSA di atas, dapat dipilih dua kandidat model persamaan HKSA terbaik. Pemilihan model persamaan HKSA terbaik tersebut dilakukan dengan memperhitungkan parameter-parameter statistik seperti harga $\mathrm{r}^{2}$ (koefisien korelasi), adjusted $\mathrm{r}^{2}$, SD (Standar Deviasi), $\mathrm{F}_{\text {hit }} / \mathrm{F}_{\text {tab }}$ dan PRESS (Predicted Residual Sum of Square).

Apabila dilihat dari harga $r^{2}$, maka semua model persamaan HKSA mempunyai harga $\mathrm{r}^{2}$ di atas 0,8 sehingga semua model persamaan HKSA tersebut memenuhi syarat sebagai model persamaan HKSA yang baik. Begitu pula untuk parameter $F_{\text {hit }} / F_{\text {tab }}$, semua model persamaan HKSA di atas mempunyai harga $\mathrm{F}_{\text {hit }} / \mathrm{F}_{\text {tab }}$ lebih dari satu sehingga memenuhi syarat sebagai model persamaan HKSA yang baik. Jika dilihat dari harga PRESS yang kecil, maka bisa dipilih dua kandidat model persamaan HKSA yang terbaik yaitu model persamaan no 4 dan 10

Untuk memilih model persamaan HKSA terbaik dari kedua kemungkinan persamaan terbaik tersebut, maka dilakukan uji validasi dengan menggunakan tujuh senyawa uji yang telah ditentukan sebelumnya. Uji validasi tersebut dilakukan dengan memprediksi aktivitas insektisida dengan menggunakan kedua model tersebut, kemudian membuat kurva hubungan $\log \operatorname{LD}_{50}$ eksperimen dengan log $\mathrm{LD}_{50}$ prediksi seperti yang disajikan pada Gambar 3 dan 4.

Tabel 3. Data perbandingan aktivitas insektisida eksperimen dan prediksi yang dihitung dengan model $5,8,13,14$ dan 15

\begin{tabular}{lrrr}
\hline Senyawa Uji & Log 1/LD & \multicolumn{2}{c}{ Log 1/LD } \\
\cline { 3 - 4 } & eksperimen & prediksi \\
\cline { 3 - 4 } & 7.43 & 7.024 & Model 4 \\
\hline Senyawa 14 & 7.99 & 7.632 & 7.613 \\
Senyawa 21 & 7.86 & 7.634 & 7.533 \\
Senyawa 23 & 8.033 & 7.571 & 7.673 \\
Senyawa 28 & 8.07 & 7.730 & 7.785 \\
Senyawa 32 & 8.02 & 7.640 & 7.695 \\
Senyawa 37 & 8.52 & 8.362 & 8.406 \\
Senyawa 46 & & & \\
\hline
\end{tabular}

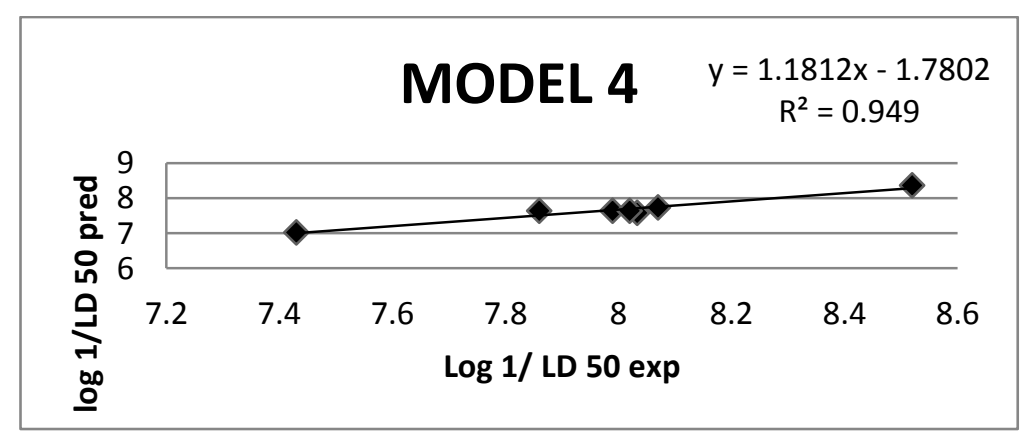

Gambar 3. Kurva hubungan $\log 1 / \mathrm{LD}_{50}$ eksperimen dengan $\log 1 / \mathrm{LD}_{50}$ prediksi untuk model 4 


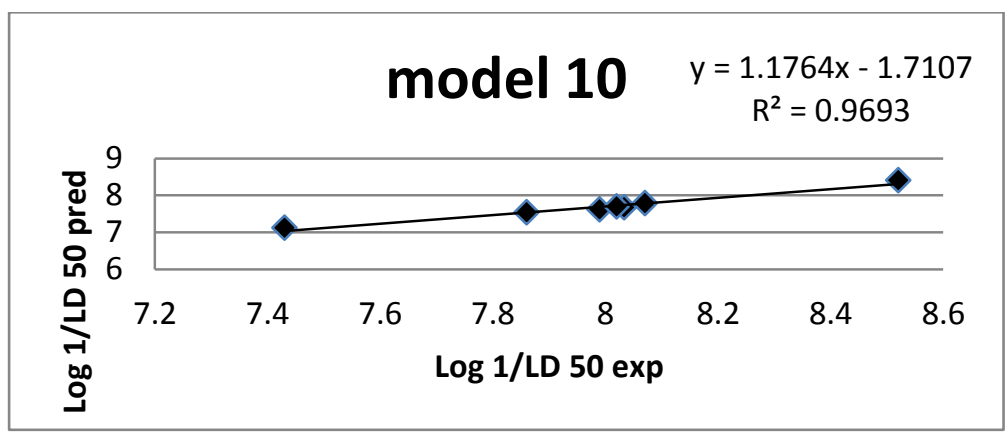

Gambar 4. Kurva hubungan $\log 1 / \mathrm{LD}_{50}$ eksperimen dengan $\log 1 / \mathrm{LD}_{50}$ prediksi untuk model 10

Kurva hubungan $\log 1 / \mathrm{LD}_{50}$ eksperimen dengan $\log 1 / \mathrm{LD}_{50}$ prediksi di atas, jika $\log 1 / \mathrm{LD}_{50}$ prediksi mendekati $1 / \mathrm{LD}_{50}$ eksperimen, maka harga slope pada kurva akan semakin mendekati satu. Oleh sebab itu untuk menentukan model persamaan HKSA yang terbaik adalah mencari harga slope yang paling mendekati satu. Dari hasil perbandingan Gambar 3 dan 4 tersebut dapat dilihat bahwa slope yang paling mendekati satu adalah model 10. Dimana pada kurva hubungan antara $\log 1 / \mathrm{LD}_{50}$ eksperimen dengan $\log 1 / \mathrm{LD}_{50}$ prediksi untuk model 4 memiliki nilai slope sebesar 1.181 dan untuk model 10 memiliki nilai slope sebesar 1.176. Dengan demikian meskipun perbedaan atau selisih nilai slope yang begitu kecil tetapi peneliti dapat menyimpulkan bahwa model persamaan HKSA terbaik adalah model 10 dengan nilai slope sebesar 1.176 dan dengan $\mathrm{R}^{2}$ sebesar 0.969. Model persamaan HKSA no 10 secara lengkap ditulis sebagai berikut :

$$
\begin{array}{r}
\log 1 / \mathrm{LD} 50=14.056+(4.976 \mathrm{qC} 2)+(6.443 \mathrm{qC} 4)-(29.519 \mathrm{qC} 6)-(2.704 \\
\mathrm{qO} 7)+(3.025 \mathrm{qN} 10)+(0.45 \mu)-(0.071 \mathrm{SA}(\text { grid }))+(0.043 \mathrm{~V})+\left(0.299 \mathrm{E}_{\mathrm{H}}\right)- \\
(0.408 \log \mathrm{P})-(0.264 \mathrm{RM})+(0.018 \mathrm{MW})+\left(0.0000181 \mathrm{E}_{\mathrm{int}}\right)+\left(0.018 \Delta \mathrm{H}_{\mathrm{f}}\right) \\
r=0.923 r^{2}=0.852 \quad S E=0.275 \quad \text { Fhit/Ftable }=4.644553 \quad \text { PRESS }=13.078
\end{array}
$$

\section{PENUTUP}

\section{Kesimpulan}

Model persamaan HKSA terbaik yang diperoleh dengan menggunkan metode Semiempirik PM3 adalah sebagai berikut :

$$
\begin{gathered}
\log 1 / \mathrm{LD} 50=12.651+(2.467 \mathrm{qC} 2)+(2.832 \mathrm{qC} 4)-(14.089 \mathrm{qC} 6)-(0.24 \mathrm{qO} 7)+(0.293 \\
\mu)-(0.08 \mathrm{SA}(\text { grid }))+(0.041 \mathrm{~V})+\left(0.141 \mathrm{E}_{\mathrm{H}}\right)-(0.303 \log \mathrm{P}) \\
r=0.839 ; \text { adjusted } r^{2}=0.612 ; \text { SE }=0.355 ; \text { Fhit/Ftable }=3.443 \text { PRESS }=5.188
\end{gathered}
$$




\section{Ucapan Terima Kasih}

Ucapan terima kasih disampaikan kepada Prof. Mudasir dan Bpk Dr Ria Armunanto Jurusan Kimia FMIPA UGM Yogyakarta atas sumbangsih saran masukan dan bimbingannya sehingga penelitian ini bisa terwujud dan terselesaikan dengan baik.

\section{DAFTAR PUSTAKA}

Armunanto R., (2004). Relation of electronic structures with their antimalarial activities on artemisinin derivatives, Indonesian Journal of Chemistry., 4(3), 212-217.

Tahir, I., Wijaya, K., Purwono, B. \& Widianingsih, D. (2003). Analisis QSAR turunan flavon / flavonol sebagai senyawa antiradikal berdasarkan analisis Hansch, Indonesian Journal of Chemistry, 3(1), 48-54.

Istyastono, Perdana, E., Martono, S., Pranowo, H.D. \& Tahir, I. (2003). Quantitative structureactivity relationship analysis of curcumin and its derivatives as GST inhibitors based on computational chemistry calculation, Indonesian Journal of Chemistry, 3(3), 179-186.

Jensen, F. (1999). Introduction for Computational Chemistry, second edition, New York, John Willey and Sons, Inc.

Kubinyi, H. (1993). QSAR: Hansh Analysis and Related Approaches, Wienhem, VCH Verlagsgesellshaft.

Mudasir, Iqmal T. \& Ida P. A. M. P. (2003). Quantitative Structure and Activity Relationship Analysis of 1,2,4-Thiadiazoline Fungicides Based on Molecular Structure Calculated by Am1 Method, Indonesian Journal of Chemistry.

Naik, P. K., Sindhura, Singh, T. \& Singh H. (2009), Quantitative structure - activity relationship (QSAR) for insecticides: Development of predictive in vivo insecticide activity models, SAR. QSAR. Environ. Res., 20(5-6), 551-566.

Pranowo, H. D. (2003), Kimia Komputasi, Yogyakarta, Pusat Kimia Komputasi IndonesiaAustria, Kimia FMIPA UGM.

Teguh, B. P. (2009), Analisis faktor risiko keracunan pestisida organofosfat pada keluarga petani hortikultura di Kecamatan Ngablak Kabupaten Magelang, Tesis S2 Pasca Sarjana, Universitas Diponegoro, Semarang. 